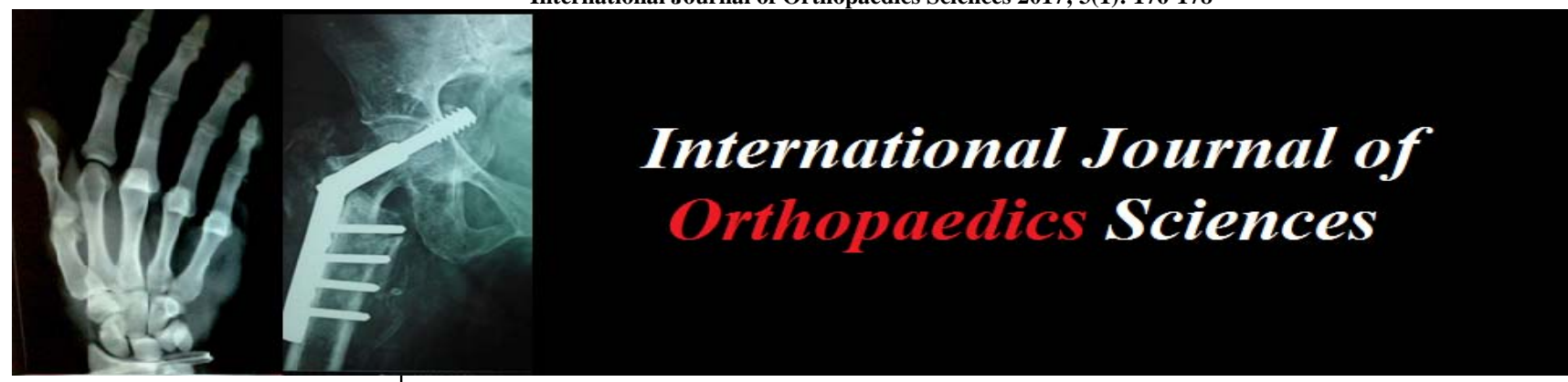

ISSN: $2395-1958$

IJOS 2017; 3(1): 176-178

(C) 2017 IJOS

www.orthopaper.com

Received: 29-11-2016

Accepted: 30-12-2016

Manoj Kumar R

Senior Resident, Department of Orthopaedics Saptagiri Institute of Medical Science and Research, Bangalore Karnataka, India

\section{Kaushik YS}

Senior Resident, Department of Orthopaedics Bangalore Medical College and Research Institute, Bangalore Karnataka, India

\section{Correspondence}

Manoj Kumar R

Senior Resident, Department of Orthopaedics Saptagiri Institute of Medical Science and Research, Bangalore Karnataka, India

\section{Functional outcome of humerus shaft fractures in adults treated by flexible nails using retrograde technique}

\section{Manoj Kumar R and Kaushik YS}

DOI: $\underline{\text { http://dx.doi.org/10.22271/ortho.2017.v3.i1c.29 }}$

\section{Abstract}

The fractures of the shaft of humerus are one of the commonest fractures found and can be treated by different methods. The present study is undertaken to know the functional outcome following the use of flexible nails for humeral shaft fractures in adults. It is a prospective study which was carried out from November 2013 to September 2016 in Saptagiri Institute of Medical science and Research, Bangalore. In this study period 20 cases of fracture shaft of the humerus were treated by closed reduction and internal fixation using flexible nails. In our series, majority of the patients were males, middle aged, with road traffic accidents being the commonest mode of injury, involving middle third. Flexible intramedullary nailing done by retrograde technique produces equally good results comparable to any plate osteosyntehsis or interlocking intramedullary nailing. Another added advantage of flexible nail fixation is it requires very minimal operative instrumentation.

Keywords: Humeral shaft fractures, flexible nails, closed reduction and internal fixation

\section{Introduction}

A fracture of the humerus shaft is commonly encountered by orthopaedic surgeons and representing between $3 \%$ and $5 \%$ of all fractures ${ }^{[1,2]}$. Given the extensive range of motion of the shoulder and elbow, and the minimal effect from minor degrees of shortening, a wide range of radiographic malunion can be accepted with little functional deficit ${ }^{[3]}$ The emphasis has changed from splinting and prolonged immobilization, to internal fixation and early mobilization, with return to normal function as early as possible The two modalities of internal fixation in fracture shaft of humerus are plate osteosynthesis and intramedullary nailing.

Current research in this area focuses on defining the incidence and health care resources required to treat this injury, refining the indications for surgical intervention, decreasing the surgical failure rate through new implants and techniques and minimizing the duration and magnitude of disability post injury ${ }^{[2,4,5]}$.

As with most orthopedic injuries, the successful treatment of a humeral shaft fracture demands a knowledge of anatomy, surgical indications, techniques and implants, patient functions and expectations ${ }^{[6]}$. With this background, this study is to evaluate the results of retrograde intramedullary flexible nailing in humeral shaft fractures and to study the duration of union in the above mentioned fractures and also the complications of flexible intramedullary nailing of humeral shaft fractures

\section{Methodology}

It is a prospective study which was carried out from October 2013 to September 2016 in Saptagiri Institute of Medical Science and Research, Bangalore. In this study period 20 cases of fracture shaft of the humerus were treated by closed reduction and internal fixation using flexible nailing.

A careful history was elicited from the patients and/or attendants to reveal the mechanism of injury and the severity of trauma. The patients were then assessed clinically to evaluate their general condition and the local injury. Standard radiographs of the humerus, i.e. anteroposterior and lateral views were obtained. 
The shoulder and elbow joints were included in each view. The limb was immobilized in a U-slab with sling. The operative procedure and its advantages were explained in detail to each patient and an informed consent was obtained.

\section{Technique}

A 5 to $7 \mathrm{~cm}$ linear longitudinal incision was put starting from the tip of olecranon process extending proximally. Divide the superficial and deep fascia. The triceps muscle is split between long and lateral head to approach the distal humerus. Using a $3.2 \mathrm{~mm}$ drill bit, 2 holes are made $1 \mathrm{~cm}$ above the olecranon fossa and $1 \mathrm{~cm}$ on either sides which are in same line. Then depending upon the diameter of medullary cavity, $2 / 2.5 / 3 \mathrm{~mm}$ flexible nail was introduced. The nail was pre bent and hammered. Progression of the nail was checked under image intensifier both AP and lateral views. Similarly second nail was passed as the first one through the second entry point. Nails are driven up into the humeral head, and an effort in made to see that the ends of the nails diverge into the head. The ends of the nails should protrude just enough to make attachment of the extractor possible.

Patients were discharged after suture removal with the arm in a humerus brace for a period of 1 month and advised to perform shoulder, elbow, wrist and finger movements. They were prohibited from lifting weight or putting additional stresses on the affected limb all the patients were followed up at monthly intervals for the first 3 months, later at 2 monthly intervals till fracture union and once in 6 months till the completion of study. They were examined in detail clinically and special stress was laid on shoulder and elbow range of movements and subjective complaints. X-rays were obtained in anteroposterior and lateral views and signs of union were looked for. The fracture was considered to be radiologically united, when there was no visible fracture line and evidence of callus bridging the fracture site. Clinical healing of the fracture was defined by the absence of functional pain and local tenderness at the previous fracture site. A detailed observation is recorded using a standard protocol.

\section{Results}

Age of these patients ranged from 18 to 70 years with 7 (35\%) patients in 4 decade. The average age was 40 years. Majority of the patients, $14(70 \%)$ were females and $6(30 \%)$ were males. We found that road traffic accidents were the most common cause of injury being responsible for $80 \%$ of cases followed by domestic accidents 10\%, fall from height 5\% and assault 5\%. There was an appreciable difference in the involvement of the sides in our series. Left extremity was more often involved $60 \%$. Right extremity was involved in only $40 \%$ of cases. 15 fractures were closed and 5 were open fractures Most of the fractures were located in the middle third of the shaft $(60 \%)$. Majority of fractures (70\%) were transverse type. In (30\%) fractures were oblique type. Follow up ranged from 6 months to 18 months. $14(70 \%)$ patients had sound union in less than 18 weeks, 2(10\%) patient had delayed union (22 Wks), 4 (20\%) patient had non-union $19(95 \%)$ patients recovered full range of motion of shoulder and elbow joint while $1(5 \%)$ patient recovered good range of motion (within $10-15 \%$ of full range).

The American shoulder and elbow surgeons (ASES) shoulder score is for 13 activities of daily living requiring full shoulder and elbow movement. The maximum possible score is 52 points. The average ASES score obtained was 50 . The number of days in the hospital ranged between 15 days and 45 days. There were no intraoperative complications. Post-operative, there was 1 case of delayed union. This pt also had shoulder and elbow stiffness which improved with exercises. There was 1 case of non-union. Non-union was due to inadequate reduction of fracture fragments and early weight bearing by the patient 1 case had implant breakage at the fracture site but fracture united uneventfully Rommens et al Series Grading32 according to which,

4.1 Excellent: Solid union - anatomic reconstitution Less than $10 \%$ loss of range of motion, no significant subjective complaints.

4.2 Good: Solid union - anatomic reconstitution, 10-30\% loss of range of motion, Minimal subjective complaints

4.3 Poor: Non anatomic results or non-union, greater than 30 degree loss of range of motion, Moderate subjective complaints. $14(70 \%)$ patients had excellent results, $6(30 \%)$ patients had poor results

\section{Discussion}

The problems inherited in the management of humeral shaft fractures today are primarily technical problems encountered in selection and application of appropriate method. The numerous methods available today allow considerable individuality in the selection of the technique. The type and level of fractures, the patient's age and cooperation of the patient, the degree of fracture displacement and presence of associated injuries are factors that influence the choice of treatment.

Most humeral shaft fractures, except those situated at the distal $2-3 \mathrm{~cm}$ of the diaphysis, are suitable for IM nailing. There are several techniques and implants available. The nails can be divided into small calibre nails (e.g. Rush-pins, Ender), bundle nails (e.g. Hackenthal, Marchetti- Vicenzi), non-locking nails (Küntscher) and locking nails (e.g. Seidel, UHN, St Pro, Russel-Taylor). According to entry site, IM nailing can be either antegrade or retrograde. The medullary canal can be enlarged (reamed) to achieve a better hold and allow larger nails to be used, or nonreaming techniques can be used. Small and bundle nails provide enough stability to maintain alignment, but they usually do not provide rotational stability and external bracing is needed. These nails can be inserted using retrograde or ante grade techniques and only a small hole is needed for Ender nails. Migration is a common problem with unlocked implants and reoperations are often needed to remove nails, although this does not necessarily affect the final outcome.

Robert et al (1987) in their prospective study, they treated 89 fractures in 88 patients with Ender nails and concluded that closed intramedullary Ender nailing can be performed safely and effectively in selected fractures of the humeral shaft. However, only fractures that are recalcitrant to closed reduction and immobilization or fractures in the non-compliant patient should be considered for this form of treatment ${ }^{[7]}$.

Zatti et al in their retrospective study of diaphyseal humeral fracture by elastic intramedullary nailing in comparison with plate osteosyntehsis, treated 14 patients with flexible nails and in the remaining 16 patients, A-O plates were used. They concluded that intramedullary elastic nailing is valid for routine use in appropriately selected humeral shaft fractures ${ }^{[8]}$. James et al (1985), in their study, closed retrograde flexible intramedullary nailing of the humerus was performed in 10 patients with retarded or delayed union. Nine fractures healed; the mean time to union was 10.5 weeks ( 6 to 22 weeks) and 
the result was successful. ${ }^{9}$ The shape, size and number of nails are determined by fracture pattern and the size of the medullary canal. The nails are contoured to correct any deformity and to secure firm fixation. An attempt is made to fill the medullary canal. Initially we used nails with diameters of $4.5 \mathrm{~mm}$, but found that the canal could accommodate only two nails. Later $3.2 \mathrm{~mm}$ nails were used ${ }^{[9]}$.

Frank et al (2008), described the use of an expandable nail for fixation of 25 unstable humeral shaft fractures in elderly patients with osteoporotic bone; all fractures healed without complications ${ }^{[10]}$.

Stannard et al (2008), used a flexible locking nail inserted through an extraarticular antegrade or retrograde portal for fixation of 42 humeral shaft fractures, with healing in 39; $86 \%$ had full range of motion, and $90 \%$ had no pain ${ }^{[10]}$.

James P. Stannard et al (2003), studied 50 consecutive patients with 51 humeral shaft fractures. The purpose of this investigation was to document the clinical outcome and complications associated with the use of a new flexible, locking intramedullary nail that can be implanted in the humerus in retrograde manner without violating the rotator cuff mechanism or damaging the articular surface of the humeral head. Thirty-nine fractures healed, with a mean time to clinical union of twelve weeks. The flexible humeral nail allows retrograde implantation and static locking ${ }^{[11]}$.

Henley (2010) reported a series of 49 patients with humeral shaft fractures treated with ender nailing and had only one non-union ${ }^{[12]}$.

The results obtained by various authors using various modalities of treatment have varied from $75 \%$ good or excellent results to $100 \%$ good or excellent results. Our study had excellent result in $70 \%$ of patients

Our results in mobility at shoulder and elbow joints are comparable with those of Bell MJ et al, McCormack RG et al. The average ASES score obtained was 50 in our series. This is comparable to the ASES score of 48 obtained by McCormack RG et al when treating humeral shaft fractures with DCP and a score of 47 when treating with interlocking intramedullary nail fixation

\section{Conclusion}

Though rigid fixation of fracture shaft humerus can be obtained using DCP/LC-DCP/LCP, it requires extensive exposure of fracture site and also disturbing the biology of fracture. Thus flexible nail fixation using retrograde technique requires very minimal soft tissue dissection and as it is a closed technique, the biology of fracture is also not disturbed. Thus early fracture union can be anticipated. Interlocking intramedullary nail also gives stable internal fixation but has its own disadvantage of rotator cuff problem when done by antegrade technique. Thus flexible intramedullary nailing done by retrograde technique produces equally good results comparable to any plate osteosynthesis or interlocking intramedullary nailing.

\section{References}

1. McKee MD. Fractures of The Shaft of The Humerus Rockwood \& Green's Fractures in Adults, 6th Edition, Bucholz, Robert W.; Heckman, James D.; Court-Brown, Charles M. Lippincott. 2006, 1118-1159

2. Brinker MR, O'Connor DP. The incidence of fractures and dislocations referred for orthopaedic services in a capitated population. J Bone Joint Surg Am. 2004; 86:290-297.

3. Wilson JN. Watson-Jones. Fractures and Joint Injuries, 6th ed. B.I. Churchill Livingstone PVT Ltd. New Delhi. 2002.

4. Colton CL, Fernandez A. Dell'Oca, Holz U, Kellam JF, Ochsner PE. AO Principles of Fracture Management: AO Publishers. 2000.

5. Klenerman L. Fractures of the shaft humerus. J Bone Joint Surg Br. 1966; 48:105-111.

6. Matthew W Lawless. Midshaft Humeral Fractures. eMedicine. 2004 July. Available from: URL: http://www.emedicine.com/orthoped/topic199.htm

7. RF Hall, Pankovich AM. Ender nailing of acute fractures of the humerus. A study of closed fixation by intramedullary nails without reaming. J Bone Joint Surg Am. 1987; 69:558-567.

8. Zatti, Giovanni, Teli, Marco, Ferrario, Andrea, Cherubino Paolo. Treatment closed humeral shaft fractures with intramedullary elastic nails.

9. James W. Pritchett. Delayed union of humeral shaft fractures treated by closed flexible intramedullary nailing. 1985; 67(5).

10. Andrew H. Crenshaw JR, Edward A Perez. Fractures of the shoulder, arm, and forearm. In: Campbells operative orthopaedics. $11^{\text {th }}$ Edn., S. Terry \& James H. Beaty. 2008; 3(54):3395.

11. James P Stannard, Howard W Harris, Gerald McGwin Jr, David A Volgas, Jorge E Alonso. Intramedullary nailing of humeral shaft fractures with a locking flexible nail. 2003; 85:2103-2110.

12. Michael D McKee, Sune Larsson. Humeral shaft fractures. In: Rockwood and Green's fractures in adults. 7th Edn. 2010; 1:34:1018. 